SHORT REPORT

\title{
Neonatal resuscitation of extremely low birthweight infants: a survey of practice in Italy
}

\author{
D Trevisanuto, N Doglioni, P Ferrarese, R Bortolus, V Zanardo, on behalf of the Neonatal \\ Resuscitation Study Group, Italian Society of Neonatology
}

Arch Dis Child Fetal Neonatal Ed 2006;91:F123-F124. doi: 10.1136/adc.2005.079772

Delivery room management of extremely low birthweight infants (ELBWIs) has been little studied. A questionnaire was sent to the heads of the 86 Italian neonatal intensive care units provided with on site delivery. The practice of and approach to the resuscitation of ELBWls were very different among the centres surveyed, reflecting a paucity of evidence and consequent uncertainty among clinicians.

$\mathrm{N}$ eonatal resuscitation remains an often practised but poorly studied intervention. ${ }^{12}$ In particular, there are no published studies specifically looking at the management of extremely low birthweight infants (ELBWIs) at birth. ${ }^{3}$

We aimed to survey the practice of and approach to neonatal resuscitation of ELBWIs in Italian tertiary centres.

\section{METHODS}

In Italy, there are 91 neonatal intensive care units; they are located in hospitals with varying numbers of deliveries (median 1560; range 500-6200), are generally small in size (median 5; range 2-15 cots), and have median 15 (range 163) ELBWIs admitted a year (Italian Society of Neonatology database).

A structured 73 item questionnaire and an accompanying introductory letter were sent by email to the heads of the 86 neonatal intensive care units provided with on site delivery. Questions covered the main areas of neonatal resuscitation based on the Neonatal Resuscitation Program (NRP). ${ }^{4}$ The questionnaire included items on the equipment and practice of the centre, and questions referred to the neonatal resuscitation of the ELBWIs during the period 1 January to 31 December 2002. The questions included multiple choice, fill in, and yes/no questions.

Data are presented as numbers and/or percentages, as appropriate.

The study was approved by the local ethics committee.

\section{RESULTS}

Information was obtained for 76 (88\%) centres. They achieved a homogeneous representation of the country (table 1).

\section{Temperature}

The median environmental temperature of the resuscitation suites was $24^{\circ} \mathrm{C}$ (range $18-31$ ). Five of the 76 centres $(6 \%$ ) routinely used a polyethylene occlusive wrap for temperature support of ELBWIs.

\section{Oxygen delivery}

Resuscitation with $100 \%$ oxygen was used at 42 of the 76 centres (55\%); at the remaining 34, various oxygen
Table 1 Centres to which questionnaires were sent and from which replies were received in relation to the geographical area

\begin{tabular}{lll}
\hline & No sent & No returned \\
\hline North Italy & 39 & 35 \\
Central Italy & 15 & 13 \\
South Italy and Islands & 32 & 28 \\
\hline
\end{tabular}

concentrations (median 40\%; range 21-70) were provided at birth in this group of patients. In the delivery suite, a pulse oximeter for transcutaneous saturation monitoring was available at 55 centres $(72 \%)$. It is routinely positioned within 5,10 , and 30 minutes in $50 \%, 88 \%$, and $100 \%$ of the centres respectively.

\section{Positive pressure ventilation}

Positive pressure ventilation was manually administered at $63(83 \%)$ centres. At the remaining 13, it was administered using a ventilator or a $\mathrm{T}$ piece circuit. Positive end expiratory pressure (PEEP) was routinely used at $26(34 \%)$ centres. The median PEEP value was $4 \mathrm{~cm} \mathrm{H}_{2} \mathrm{O}$ (range 3-6).

\section{Intubation}

At birth, intubation of ELBWIs was based on an individualised strategy at $66(87 \%)$ centres. Oral intubation was the preferred route at $40(53 \%)$ centres; at the remaining 36 $(47 \%)$ nasal intubation was routinely performed.

During 2002, 791 of 1072 ELBWIs $(73.7 \%)$ born at the 68 responding centres were intubated at birth.

\section{Chest compressions}

Of the 72 responding centres, $22(30 \%)$ used the two thumb technique, $18(25 \%)$ the two finger technique, and $32(46 \%)$ both methods. In 2002, 230 of 1061 ELBWIs born at the 66 responding centres $(21.6 \%)$ received chest compressions.

\section{Drugs}

Drugs were administered to 93 of 1061 ELBWIs (8.7\%). Of these, $86(92 \%), 21(22 \%)$, and three $(3 \%)$ received adrenaline (epinephrine), bicarbonate, and volume expanders respectively.

Thirty centres (39\%) routinely administered surfactant in the delivery setting, and all used natural surfactant preparations. Of these, 17 (57\%) administered surfactant therapy to all preterm infants of gestational age $<28$ weeks (range 2634); the remaining 13 treated all ELBWIs needing intubation for resuscitation.

Abbreviations: ELBWI, extremely low birthweight infant; NRP, Neonatal Resuscitation Program; PEEP, positive end expiratory pressure 


\section{What is already known on this topic}

- There is a lack of information on delivery room management of extremely low birthweight infants

\section{DISCUSSION}

There is a lack of information about the delivery room management of ELBWIs. ${ }^{3}$ As adequate management of this group of patients at birth could be very effective, we aimed to evaluate neonatal resuscitation in this high risk population.

Our data reflect the practice of the vast majority $(88 \%)$ of Italian tertiary centres in relation to the most crucial points of ELBWI management at birth. On the whole, we found large differences among the participating centres, showing that the application of the NRP guidelines in the clinical setting is low. ${ }^{4}$ Some showed apparently high compliance with the NRP guidelines-for example, provision of 100\% oxygen. Others showed a different approach based on the results reported in recent studies evaluating specific interventions in this group of patients at birth-for example, the use of a polyethylene occlusive wrap, the administration of low oxygen concentrations, the use of PEEP. ${ }^{13}$

Furthermore, our data show that a large proportion of the ELBWIs born at Italian tertiary centres were intubated (74\%), and received chest compression (22\%) or drugs (9\%). These percentages are very different among the participating centres. However, they are higher than in other studies, and need further evaluation.

In conclusion, this survey shows that management of ELBWIs at birth is very different across Italian tertiary centres, reflecting a paucity of evidence and consequent uncertainty among clinicians. Further prospective research in this field is needed.

\section{What this study adds}

- This survey shows that management of these infants at birth is very different across Italian tertiary centres, reflecting a paucity of evidence and consequent uncertainty among clinicians

\section{ACKNOWLEDGEMENTS}

We acknowledge Dr Paola Vettorel for revising the manuscript, and the heads of the participating centres for their assistance with this survey.

\section{Authors' affiliations}

D Trevisanuto, N Doglioni, P Ferrarese, V Zanardo, Department of Paediatrics, School of Medicine, University of Padova, Padova, Italy R Bortolus, International Centre on Birth Defects, Rome, Italy

Competing interests: none declared

Correspondence to: Dr Trevisanuto, Department of Paediatrics, University of Padova, Via Giustiniani, 3, 35128 Padova, Italy; trevo@ pediatria.unipd.it

Accepted 7 September 2005

\section{REFERENCES}

1 Finer NN, Wade DR. Neonatal resuscitation: raising the bar. Curr Opin Pediatr 2004;16:157-62.

2 O'Donnell CPF, Davis PG, Morley CJ. Positive pressure ventilation at neonatal resuscitation: review of equipment and international survey of practice. Acta Paediatr 2004;93:583-8.

3 O'Donnell CPF, Davis PG, Morley CJ. Resuscitation of premature infants: what are we doing wrong and can we do better? Biol Neonate 2003;84:76-82.

4 Kattwinkel J, ed. Neonatal resuscitation program: textbook of neonatal resuscitation, 4th ed. Washington DC: American Academy of Pediatrics/ American Heart Association, 2000

5 Finer NN, Horbar JD, Carpenter J. Cardiopulmonary resuscitation in very low birth weight infants: The Vermont Oxford Network Experience. Pediatrics 1999; 104:428-34.

\section{Committee on Publication Ethics - Seminar 2006}

\subsection{0am-5pm Friday 10th March 2006, BMA House, London, UK}

This year's seminar takes an international perspective and addresses publication ethics and research in several European countries and beyond, with interactive workshops on common ethical and editorial dilemmas. The manipulation of impact factors, and whether unethical, will also be considered.

The seminar is for editors, authors, and all those interested in increasing the standard of publication ethics. The seminar will include:

- Professor Michael Farthing - the Panel for Research Integrity (UK)

- Publication ethics and research in other countries, including those in Northern Europe, Turkey, and China

- Publication ethics in animal research

- Making the COPE website work for you - real time demonstration on how to use the website

- New indexing services

- Interactive workshops - common ethical and editorial dilemmas for editors

- Opportunities to network with other editors and share your experiences and challenges The seminar is free for COPE members and $£ 30.00+$ VAT for non-members. Numbers are limited and early booking is advisable. For registrations or more information please contact the COPE Secretary at cope@bmigroup.com or call 020-7383-6602

For more information on COPE see www.publicationethics.org.uk 